\title{
Development and Application of an Autonomous Learning System for Engineering Graphics Education
}

\author{
Weiwei Song \\ School of mechanical engineering, University of Jinan, Jinan, China \\ Email: me_songww@ujn.edu.cn \\ Shukun Cao, Bo Yang, Kaifeng Song and Changzhong Wu \\ Name of Institution/Department, City, Country \\ Email: \{me_songww \}@ujn.edu.cn
}

\begin{abstract}
Autonomous learning plays an important role in raising students' learning effect and innovation ability in university education. An effective e-learning environment is indispensable in autonomous learning. This paper studies a web based e-learning system and examines students' autonomous learning ability and perceptions of e-learning taking students at University of Jinan in China as an example. In this paper, a web-based e-learning system for engineering graphics course is developed. The characteristics, the design idea and strategies fit for engineering graphics are introduced. The architecture and system composition are discussed. The key technologies and implementation methods of each module of system are described in detail. The students had experiences on the network learning system for two years. The practical application indicates that it can enhance students' perceptual cognition to the teaching contents, increase their learning interests, develop their learning initiative and make them master the teaching contents more quickly.
\end{abstract}

Index Terms - engineering graphics; web-based learning system; autonomous learning

\section{INTRODUCTION}

The $21^{\text {st }}$ century has been an era of innovations in mass media, information and communication technologies (ICTs) growing so rapidly, many enormous changes have been taken place in people's lifestyle, working mode, and learning situation. ICTs are also becoming progressively more widespread throughout the educational field. The traditional spoon-feeding teaching mode has already unable to meet the demands of the development of modern higher education. Training and improving students' autonomous learning ability is currently becoming a relevant research topic. The rapid development of multimedia technologies such as audio, video, visual aids, interactive multimedia and the internet

Project number: XBS0909, corresponding author: Weiwei Song increases the efficiency of the teaching process and allows students to more readily remember information. Network, a kind of new information carrier, is the extension of books and audiovisual media. It is easy to be accepted and becomes more and more welcomed by college students for its more information capacity, multifunction, and higher efficiency [1]. So web-based autonomous learning is going to be an important educational trend. Web-based learning systems make it possible to learn actively and individually. Therefore, constructing an autonomous learning environment, as well as investigating autonomous learning mode is important research topics in educational field.

Engineering graphics, as an important technical basic course with strong practicality of engineering students, plays an important role in engineering discipline, cultivating students' ability in their spatial imagination, manipulation and innovation, and learning subsequent specialized courses. Especially in recent years, with the developing of information technology, engineering graphics also enters a new age. Three dimensional design, virtual reality and computer network integration technology have changed the ideas of design and drawing. These new technologies add new contents to the ancient subject; moreover, they also raise new requirements to its teaching mode. Presently, computer aided instruction (CAI) has been applied widely in Engineering Graphics teaching and obtained good teaching effects. But, there are still no enough class hours to guide students to master classroom teaching content skillfully as well as apply them. Some students usually feel difficult in learning this course. Therefore, it is necessary to construct a proper learning environment and improve the students' autonomous ability after class. In this paper, we summarize the results of our previous research work [2, 3] and construct a web-based e-learning platform.

In the next section, the paper introduces the related work. Section 3 describes the design idea, system composition, and the architecture of the learning system. Section 4 talks about the key technologies and the system implementation. Section 5 studies the application of the 
system. The last section makes a conclusion and talks about future work.

\section{RELATED WORK}

The principle of constructivism is that students are by no means passive receptacles of information. Instead, they are the central focus in learning. Students are actively responsible for their own learning, and teachers should make students construct their own understanding of the course using a variety of ways. The teacher's role is to guide students to learn by themselves instead of spoonfeeding.

The concept of autonomous learning has been raised for a few years, and nowadays become a buzzword in the education area. Many theorists [4, 5] define autonomy in many different ways. But the main idea is that the learner should have much of the responsibility for planning and organizing their learning, for assessing its value to his or herself and even for suggesting the mark that the work produced should get. And teachers should be information provider, counselor, administrator, organizer, and so on.

A good learning environment is the guarantee for students to construct their own meaning in the process of learning. Nowadays, in university education, web based e-learning system are used for distance tuition, which can create a complement to teacher-controlled tuition on campus [6, 7]. E-learning is a relatively new concept implying learning by means of digital media such as computers, web pages, video conference systems and CD-ROMs [8]. In recent years computer programs for elearning, consisting of tools such as text, graphics, video, three-dimensional objects and animations, have been developed. Virtual classrooms can be used to broaden educational services[9]. With the development of education technology and the demands of the major, many web-based teaching systems for engineering graphics have been developed. But most systems focus to the building of model library or courseware. They usually satisfy to lecture but less fit for autonomous learning after class. The research on the autonomous learning system for engineering graphics is relatively rare. Aim at this kind of circumstance; we put forward an autonomous learning system in this paper, which provides an ideal autonomy learning environment. The learning system includes online learning system, online testing system, homework system, question and answer system and learning resources library.

\section{SyStEM ARChITECTURE AND DESIGN}

Autonomous learning based on web should be an organized active and collaborative learning instead of indulgent self-study. So the learning system should meet two basic requirements at least, that is teachers' instruction and students' participation. For example, teachers should be able to choose the courseware according to teaching content, upload their own electronic teaching notes, make the courseware online or assign and check the homework by learning system. Meanwhile, Students also can learn to their individual

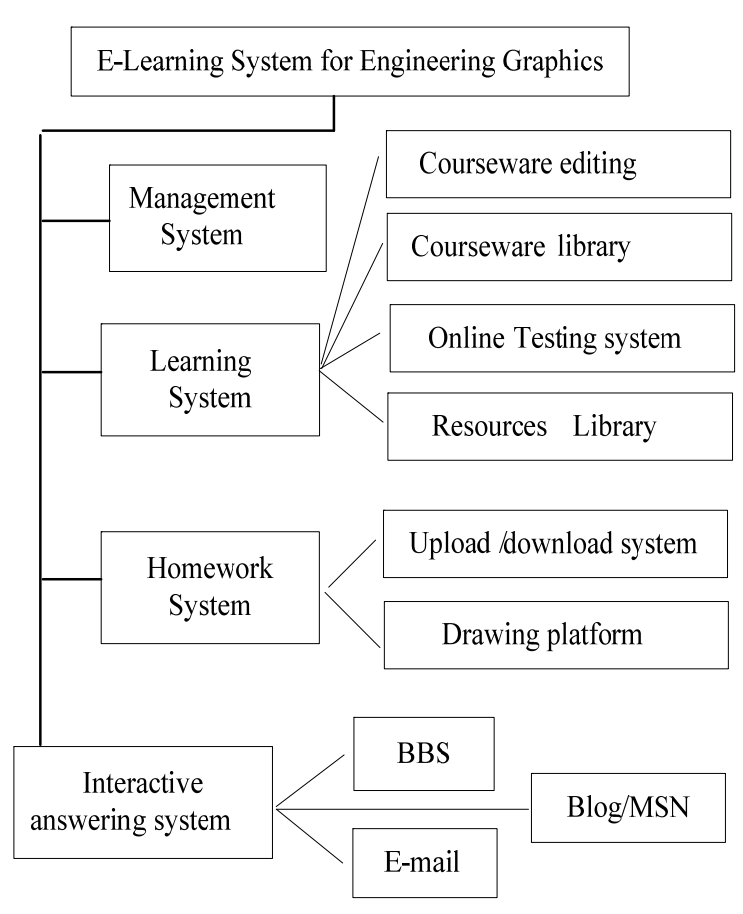

Figure 1. Architecture model of web-based learning system of Engineering Graphics.

situation, do homework, communicate each other online or self-test by using the system. According to these requirements and characteristics of the course, we propose the system structure model of e-learning system of engineering graphics as shown in Fig. 1. The whole system is composed of management system, learning system, homework system and interactive answering system. Among them, the management system is responsible for login, update and database management.

\section{A. Learning system design}

In network environment, students can control their own learning progress by themselves, so an effective user interface is essential to the enabling of students who try to explore knowledge presented in the learning environment and in monitoring their own learning progress avoid overwhelmingly complicated content. Besides, in learning systems, courseware design and management are indispensable parts. On the one hand, the design principle of courseware in web-based learning system must be student-centered, and be suitable to students' autonomous learning after class. On the other hand, the number of various courseware increases, how to find the courseware or learning materials that are most suitable or interesting to students is a practical problem. Many designers pay much more attention in establishing a learning system but ignore to judge what material is proper for students. Usually, Students who study by the network come from different specialties, which leads to the class hours and contents of studying engineering graphics are different. Besides, Everybody's ability has a very great difference too. Therefore, Network teaching system should have the characteristic of adaptability, that is to say, the system should show dynamically teaching 
contents that are the most correlative with learner. For instance, the system can choose the contents that students did not study or did not understand automatically according to their study records, so the learning contents that the system has selected would be nearest to student's current ability. In addition, the display modes of teaching contents are also different for different learners. In a word, the adaptable teaching system should have follow functions: the dynamical adaptability of teaching contents, the adaptability of navigation, the adaptability of display mode, the adaptability of asking questions and the adaptability of selecting study strategy.

In this paper, we present a model of courseware management system (Fig.2) that is appropriate for autonomous learning.

The system integrates the management of various teaching resources and a courseware editor. The editor is a multi-media integration platform which possesses the function of integrating, editing, searching, management and publishing. Using it, teacher can integrate various multi-media materials from resources database to form a complete electronic lecture and display it on the network directly.

A resources library is another important part of the learning system, because the Engineering Graphics is the course that based mainly on graphics. Resources library which includes 3D training models, 2D engineering drawing, dynamic virtual models, and simulation animations, can be helpful for students to further exercise and understand the course contents after class.

In addition, online test system is an indispensable part too. In learning process, students can know their level of learning at any moment by testing system.

\section{B. Homework System Design}

The homework after course is very important for learning the Engineering Graphics lesson because of its strong practicality. So, teachers have to spend too much time in correcting students' homework. How to lighten the teacher's burden effectively but still meet the

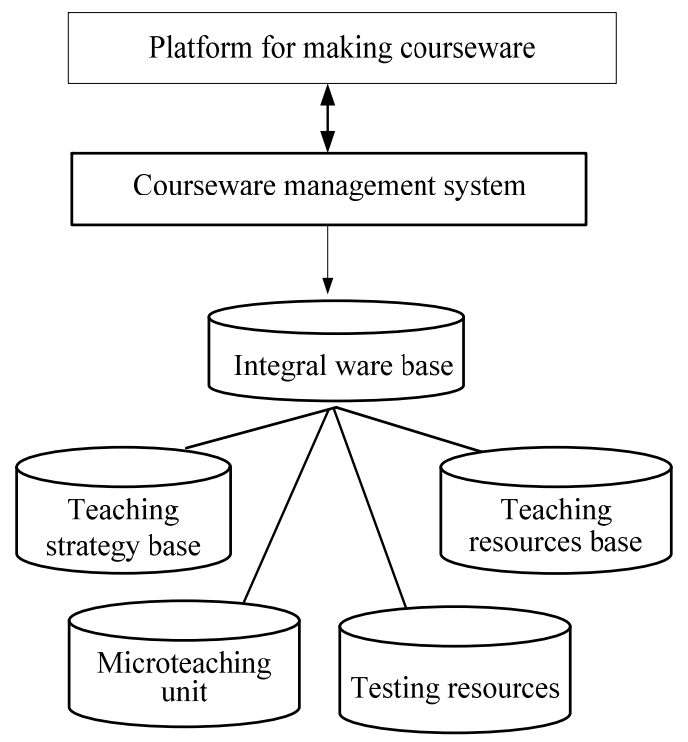

Figure.2. Model of courseware management system.

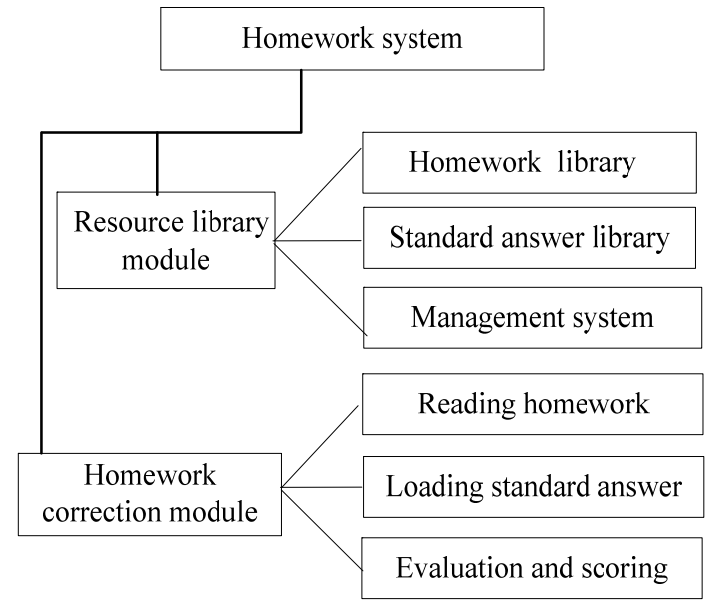

Figure.3. Model of courseware management system.

demands of course training is the problem being considered in developing network learning system. Therefore, we design an intelligence homework system innovatively in our system. The architecture of homework system is shown in Fig.3, it includes two modules: graphic library module and homework correction module. In homework correction system, we apply the theory and method of pattern recognition. A standard answer is considered as a template to match the graphic in homework automatically by the template matching algorithm.

The exercises are saved in the homework library with “.dwg” format and “.exb” format. Students can use corresponding AutoCAD or CAXA drawing environment to practice online while click the topic, or download the homework to local hard disk to finish them. The finished homework could be uploaded through the homework management system and be evaluated by correction system. After uploading their homework, the students can get the correcting results immediately. The realization process of homework management system will be described in another paper.

\section{Intelligent Answering System Design}

Being the continuation of classroom teaching, the communication among teachers and students is an important aspect in teaching activities. Network makes the communication more easy and convenient. There are many communicating style on internet, such as whiteboard, video meeting, BBS, Blog, E-mail, MSN/ICQ and general text chat. Among them, BBS is an extremely popular form of communication for teaching and students and has been used in various teaching systems widely. Once logged in, teachers or students can perform functions such as uploading and downloading software and data, reading news bulletin, and exchanging messages with other users. Using BBS, teachers can participate in discussion, answer questions or instruct students to discuss a certain topic [4, 5]. We also design a BBS-based answering platform in our learning system, but different from traditional BBS, our answering system has intelligent characteristics. The intelligent answer 
system we designed is an adaptable repository system, which is divided into two parts of automatic answer and manual answer. In teaching design stage, teachers put the most familiar difficulties and questions in repository of a course. While meeting questions, students could send the description of questions to the system, and then system would search the repository and present the solution to the students intelligently according to the questions. If there were not proper solution of that question, the system would notify the student and then change to the mode of E-mail or BBS system.

\section{Management System Design}

Teaching and a resources library both plays an important role in the network teaching system. A completed teaching resources library is the basic guarantee for the learner to study efficiently. It is made up of two parts: CAI software library and study resources library. The CAI software library includes various domestic or international excellent coursewares that are collected by every kind of avenues, which may be a complete course, also likely to be a section lesson or a knowledge keystone. The CAI software in the library should have diverse form and abundant contents to suit the demands of different courses or different level. The study resources library provides abundant study background materials, additional materials and other multi-media materials. For the engineering graphics, 3-D solid models, engineering drawings and cartoons should be main recourses in its teaching recourses library. Facing so many teaching resources, how to collect, manage, index and make use of them should be focused in the process of building network courses.

In our autonomous learning system, we design a management module to support each part of the webbased system, including register, student's status management, professional curricular management, the data statistic and analysis, information search, document management and system setup or maintenance. Because there are too many modules and teaching resources in the learning system, we design the database for each module respectively. Then, when one of the modules needs to be expanded or updated, the others could work normally.

\section{E. Interactive Design}

When we design an interactive teaching program, the learners' characteristics must be analyzed, and the right of deciding learning process and sequence should be granted to learners. Ideal interactive teaching should be fit for every learner's knowledge level and their learning method. The interaction of the autonomous learning system is an important factor that influences learning effect and is the important basic of independent learning. Without interaction, there will be no communication. In the design of teaching system, interaction concerns many aspects, of which very important one is the design of navigation, i.e. the interactive design between the learners and learning information. Right navigation enables students to make full use of teaching resources, to select learning contents and to make a learning plan by themselves, eventually to improve their learning efficiency.

The navigation is different because of different contents and functions. In order to make students select their expected contents freely, knowledge point is used as the beginning of searching route in the system presented in this paper. Those contents relating to certain knowledge point, such as analysis, explanations, examples and exercises and so on, constitute a multibranches tree by hyperlinks. This design of navigation is powerfully interactive and optional, and provides students with a convenient and active learning platform.

\section{F. Web page Design}

Web pages are used to deliver the knowledge to students as the interface of this system to the users. In order to make the computer to be the replacer of teachers who teach knowledge communicate with students, the rule of students' cognition and perception should be pay great attention to, and with network information technology and media represent technology effectively applied, we can deliver teaching knowledge they need to learn in proper ways. Pay too much emphasis on network technology, web page is showy. Teaching is the center, and the application of network technology is used to maximize the effect of teaching, so the media represent way should be capable of representing the purposes of the teaching content.

The web based teaching system is made into the form of electronic teaching materials, which displays the contents of the teaching materials on web pages directly. The interactivity between learners and learning materials only is defined as the act of changing page when reading, in this way the autonomous learning can only be represented on the freedom of the learning time choosing.

Engineering graphics is a subject which research on the methods to solve spatial geometry problems, all contents in this subject, for example, concepts and examples and so on is about the specialty geometry problems, so that graphics play an important role in the course. When the web pages are designed, all examples and problems on certain knowledge point should be placed on one page, including the links of explanation of the concept, correlative examples and exercise and so on. Graphics and text are combined in one page which includes not only the static images, but also the dynamic demo process, so we can explain the content clearly in the briefest way. Button should be designed as regularly as possible, and caption of button should be explicit and brief, so the learner can search what they want quickly and precisely.

\section{The Key IMPLEMENTATION TECHNOLOGIS}

At present, many network development tools have been used, each kind of tools has its own advantages. Considering the teaching resources library of engineering graphics is large in quantity and various in style, we adopted three layers $\mathrm{B} / \mathrm{S}$ structure as the network structure, employed PHP+ Apache+ MySQL as the main technology to develop the management system. In 
programming, a modular PHP developing technology is proposed. This programming method makes the code structure simplification and standardization. So it is easy to maintain and extend.

\section{A. About the B/S Structure}

The Browser/Server (B/S) structure is used in developing the system instead of traditional Client/Server(C/S) mode because that the network learning system is an open system, and the resources database needs to be expanded and updated continuously. But the client in $\mathrm{C} / \mathrm{S}$ system must be installed various corresponding applications to a certain system. It is a "fatty" client and can not meet the requirement of the information globalization and the customer diversifications. Different from it, on the client of the B/S structure, users only needs to install Web browser instead of any other procedure. It is a kind of "thin" client system, which all applications and data information of the system are saved on the server. Users browse through the websites on their browsers, and that all calculation operation and calculation processing are completed by applications on the server.

\section{B. PHP + Apache+ MySQL Technology}

The reason that we select $\mathrm{PHP}+\mathrm{Apache}+\mathrm{MySQL}$ as the developing technology is that $\mathrm{PHP}+\mathrm{Apache+MySQL}$ are regarded as the best combination technology to develop dynamic websites now. MySQL can combine with PHP seamlessly; and Apache Web server [6] is one of the most popular web servers on the Internet at present, it is high-efficient, reliable, easy to expand, powerful, and all source codes are free. The combination of these three technologies is especially suitable for small and medium enterprises and educational institutions, it is low to spend, but there is higher performance.

\section{Developing princeple and implementation of Modular PHP program}

The PHP files corresponding to each function modular are composed of many parts. If each part in a PHP file is saved as an individual modular, then the whole file can be regarded as a combination of these independent modular.

In system implementation, we conclude four kinds of system modular according to its nature and function. They are signed by file extension name. Among them, ".mod" file is the template file of HTML which used to construct the page. ".inc" file is to display a certain page. “.form” file is to display text in a certain page. “.php” file is a PHP program file to implement the function integration of other modular. This modular PHP developing method makes code structure clear and easy to design and maintain. In addition, some code maybe be used many times in various modular, using the modular PHP developing method can share these code in different modular.

The web-based learning system has been implemented according to above design thinking and technology. Here are some images of screen-capture of the system environment: Fig. 4 shows the page of learning system and a model library.
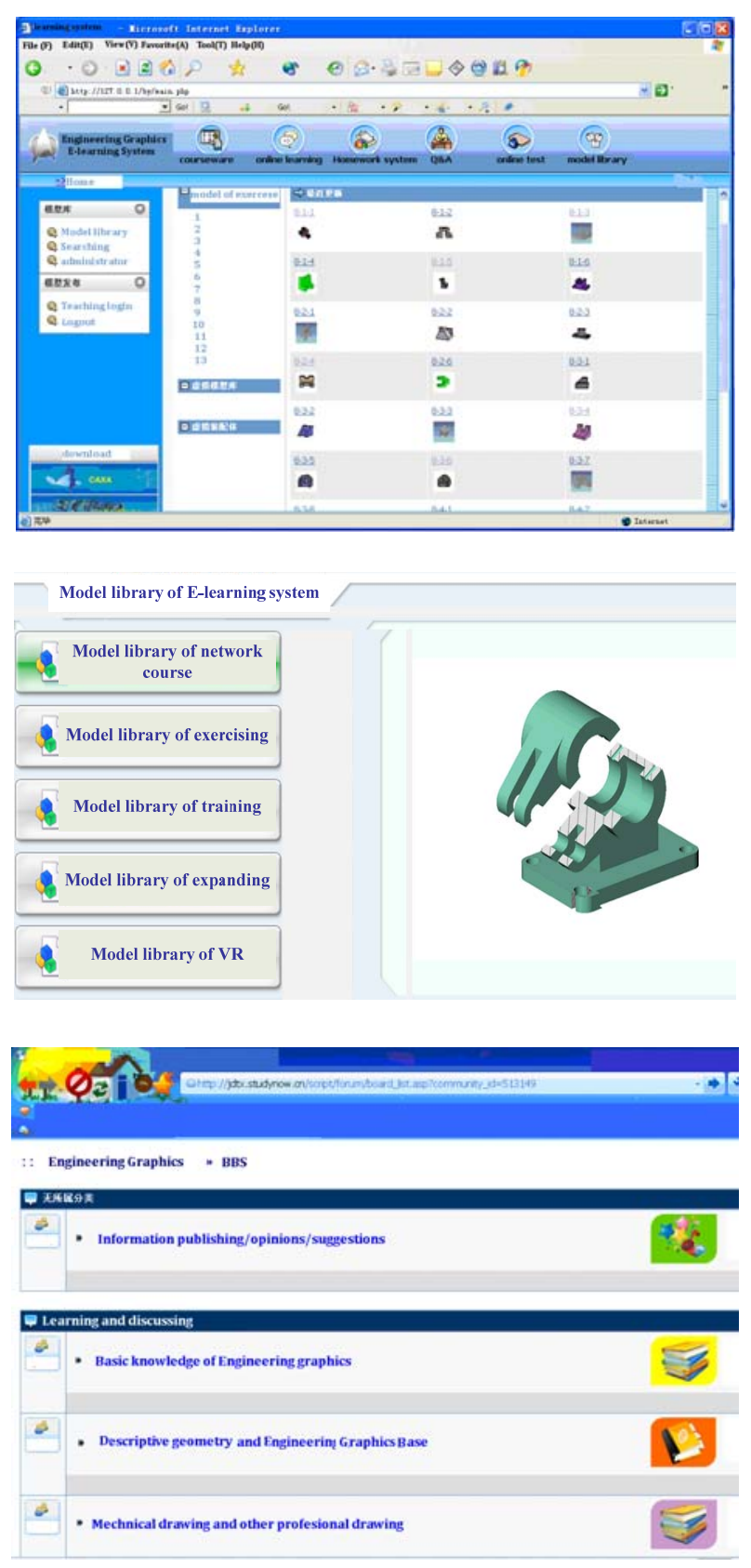

Figure.4. Model of courseware management system.

\section{ApPlication Of The E-LEARNing SYSTEM}

The system discussed in this paper is an ideal environment for students to learn on their own terms. Using the system, we studied the automous learning in the course of engineering graphics for the students of mechanical engineering.

\section{A. Teaching experiment and arrangement}

Five classes with 2000 mechanical engineering major college students enrolled in the year of 2008. Teaching experiment, interview, questionnaire, observation and examination are utilized for data collection in this study. Interview and questionnaire aim to seek information 
about students' opinions on the new teaching mode while teaching experiment is to present a reformed teaching mode adopted in engineering graphics.

Teachers still play very important role in cultivating students' learning autonomy ability. They usually guide students to the right way in the process of learning. So, as teachers, they should teach students how to learn instead of learning itself, introduce the necessity and feasibility of autonomous learning as well as facilitate them to be autonomous learners in the end.

For the experimental students, a new multimedia teaching mode is introduced, which is characterized as web-based autonomous learning. For the other students, a traditional multimedia teaching mode is still adopted.

\section{B. Experimental Method}

In new teaching mode, much attention is paid to cultivate the students' autonomous learning. Two stages were adopted in the experiment.

The first stage is teacher-instructed autonomous learning. During this period, one hour's in-class period is assigned to teach the main knowledge points. The teacher dominates the whole class and help students grasp the basic theory and method. In the period of the next half of an hour, the teacher arranges some contents for students to learn autonomously in e-learning environment. Students apply various resources in the learning system to finish the assigned tasks individually and independently. While students study, the teacher should go around making sure that every student is concentrating on their studies. That will help teacher to get the general information about students' learning. Besides in-class period autonomous learning, a certain times autonomous learning after class are also offered to the students. Students can fulfill their studies by using courseware and other teaching resources in the e-learning system, finish their assignments online and consult the feedbacks from their teacher. In this way, their learning can be adjusted accordingly. In this primary stage, the teacher tries his best to help students master the skills of autonomous learning, organize their learning by the e-learning system, and therefore, improve students' learning interests.

The second stage is non-instruction autonomous learning. After the first-stage training, students had mastered some autonomous learning skills. In class, with their teacher's help, students can design their learning plans; select specific learning tasks, adjust their learning and then improve the efficiency of autonomous learning. After class, students are free to study online. They can choose different learning materials based on their interests and their capacities. When they meet questions, they can make contact with their teacher through E-mail or BBS whenever they want. According to the assessment from the teacher, some measurements will be taken to enhance their learning. In this way, students' intrinsic motivation is inspired; as a result, they become interested in learning and communicate with others.

\section{Experimental Results and Discussion}

After two academic years of teaching, by analyzing the results of questionnaire and the scores of students belong to different groups, we found that the attitude of the students in experimental group towards the studying is active, and their scores are higher than the nonexperimental group generally. This proves that the new teaching mode for cultivating students' autonomous learning ability is effective. Comparatively speaking, it is advantageous over traditional teaching mode. As to the results from the questionnaire, most students in experimental group have become more confident while studying. From comparing the scores of different groups, we know that web-based autonomous learning system provides an excellent environment for engineering graphics learning.

\section{CONCLUSIONS}

The work presented in this paper describes a complex autonomous learning system of Engineering Graphics and its application. The practice on the system has been carried out for two years and thousands of students participated in it over this period of time. Two years teaching practice shows that the method of learning was appreciated by the students who worked hard. It is not only able to save teaching time and enhance teaching quality and efficiency, but also stimulate students' learning interests, develop their learning initiative. Further more, the improvement of autonomous learning ability, has important significance to improve students' innovation ability, train their cooperative consciousness and raise the ability of analyzing and solving problems independently. Now, students have accepted the teaching system extensively.

The teaching practice also proved that we can use information and multimedia technologies to supplement classical learning with good learning results and to provide a pleasant learning experience for the students.

As an e-learning system, the intelligence of system is an important property. Intelligent searching and resources recommendation system, which can recommend learning resources best reflecting the true interests of different learners, is our future research direction.

\section{ACKNOWLEDGMENT}

This work was supported in part by Doctoral Fund of University of Jinan (XBS0909) and educational foundation of University of Jinan (JZC0917).

\section{REFERENCES}

[1] R. Anane, S. Crowther, J. Beadle et al., "E-Learning Content Provision,” Proceedings of the 15th International Workshop on Database and Expert Systems Applications (DEXA’04), Aug.-Sept. 2004,pp.420-425.

[2] W.W. SONG, Q. ZHAO, H. AN, "The Reform and Practice of Engineering Graphics using CAXA," In: Proceeding of the 7th CJJCGE, 2007, pp.24-26.

[3] W.W. SONG, Q. ZHAO, H. AN, L.N. LIU, "Design and Implementation of the Network Teaching System Based on Integral Ware(in Chinese)," Journal of Engineering Graphics, 2006,vol.27,no.1, pp. 138-142.

[4] L. Dickinson, Self-instruction in Language Learning. Cambridge: Cambridge University Press, 1987. 
[5] H. Holec, Autonomy and Foreign Language Learning. Oxford: Pergamon Press,1981.

[6] J. Cross, "A history of e-Learning”, http://www.scribd.com/doc/12913198/History-Future-ofeLearning-On-the-Horizon ,2010.

[7] I. Bhattacharya, K. Sharma, "India in the knowledge economy -an electronic paradigm,” International Journal of Educational Management, 21(6), pp.543-68, 2007.

[8] H. Tang Lin and Shyan Ming Yuan, "Taking Blog as a Platform of Learning Reflective Journal,” In: LNCS, vol. 4181, W. Liu, Q. Li, and R.W.H. Lau, Eds. Springer, Heidelberg, pp. 38-47, 2006.

[9] T. Rebedea, S. Trausan-Matu, "Computer-Assisted Evaluation of CSC," Chat Conversations, accepted at CSCL 2009: CSCL Practices (2009)

[10] "The Best Bets for Web Development", http://www.apache.org.

Weiwei Song was born in Weihai, China, in 1968. She received the M.D. degree in mechanical design and theory from Shandong University, Jinan, China, in 2000 and received the Ph.D.degree in mechanical design and theory from Dalian University of Technology, Dalian, China, in 2008.
She was an assistant professor in the school of mechanical engineering, University of Jinan. Her specialities are computer graphics, engineering graphics and computer assisted design.

Dr. Song is a Member of China Graphics Society and Mechanical Engineering Society.

Shukun Cao was born in Jinan, China, in 1970. He received the M.D. degree and Ph.D. degree in mechanical design and theory from Shandong University, Jinan, China, in 2000 and 2005 respectively.

He was a professor in the school of mechanical engineering, University of Jinan. His specialities are mechanical CAD/CAM/CAE.

Dr. Cao is a Member of Mechanical Engineering Society.

Yang Bao was born in Heilongjiang, China, in $1968 \mathrm{He}$ received the M.D. degree and Ph.D. degree in mechanical design and theory from Shandong University, Jinan, China, in 2001 and 2005 respectively.

She was a professor in the school of mechanical engineering, University of Jinan. His specialities are mechanical design and modern design method.

Dr.Yang is a Member of Mechanical Engineering Society. 